\title{
Ganho de peso, hemoglobina e hematócrito de ratos recebendo dieta de Quissamã, RJ, com ou sem suplemento alimentar alternativo ${ }^{1}$
}

\section{Weight gain, hemoglobin and hematocrit of rats receiving the Quissamã's diet with or without an alternative food supplement}

Gilson Teles BOAVENTURA ${ }^{2}$

Renata Helena de Lima e SILVA ${ }^{3}$

Laura Fraga TOSTES 3

Vilma Blondet de AZEREDO²

\section{RE S U M O}

Avaliou-se o suplemento alimentar alternativo adicionado à Dieta de Quissamã, consumida por crianças desnutridas inscritas no Subprograma da Multimistura da Secretaria de Saúde do município de Quissamã, RJ. 0 ensaio biológico foi desenvolvido durante 28 dias com 42 Rattus norvegicus, Wistar, machos ( 26 dias), do Laboratório de Nutrição Experimental da Universidade Federal Fluminense, divididos em sete grupos: 1) Grupo Controle (dieta à base de caseína) adicionado de vitaminas e minerais; 2) GCvm adicionado do Suplemento Alimentar; 3) Grupo Controle adicionado do Suplemento Alimentar; 4) Grupo Quissamã, à base da Dieta de Quissamã; 5) Grupo Quissamã adicionado de vitaminas e minerais; 6) GQvm adicionado do Suplemento Alimentar; e 7) Grupo Quissamã adicionado do Suplemento Alimentar. Água e ração foram ofertados com livre acesso, e o pesos dos animais e o consumo de ração foram medidos a cada dois dias. 0 sangue foi coletado no 28 - dia para análise. 0 Grupo Controle adicionado do Suplemento Alimentar apresentou perda de peso significativa $(p \leq 0,05)$ comparada aos demais grupos e níveis de hemoglobina e hematócrito significativamente elevados em relação aos demais Grupos Controles. O Grupo Quissamã apresentou o maior valor de hemoglobina e o Grupo Controle adicionado do Suplemento Alimentar obteve o maior valor de hematócito, dentre todos os grupos que receberam ração de Quissamã. A suplementação da Dieta de Quissamã não se mostrou necessária neste experimento.

Termos de indexação: ganho de peso, suplementação alimentar alternativo, hemoglobinas, hematócrito.

\footnotetext{
1 Trabalho desenvolvido com Bolsa de Iniciação Científica e Auxílio à pesquisa da FAPERJ, Processo no E-26/170.613/2000 e Bolsa de Iniciação Científica do PIBIC/UFF/CN Pq.

2 Departamento de N utrição e Dietética, Faculdade de N utrição, U niversidade Federal Fluminense. R. São Paulo, 30, 4ํandar, Centro, 24015-110, Niterói, RJ, Brasil. Correspondência para/Correspondence to: G.L. BOAVENTURA. E-mail: gilsontb@gbl.com.br; gilsontb@vm.uff.br

3 Nutricionistas.
} 


\section{A B S T R A C T}

This study evaluated an alternative food supplement added to the Quissamã's diet, which is consumed by malnourished children who participate in the Multimixture Subprogram, developed by Quissamã Municipal Health Authority, in the state of Rio de Janeiro. The biological assay was carried out during 28 days with 42 male Rattus norvegicus, Wistar, 26 days old, obtained from the Experimental Nutrition Laboratory at the Fluminense Federal University, divided into seven groups: 1) Control Group (diet based on casein) added with vitamins and minerals; 2) CGvm added with Food Supplement; 3) Control Group added with Food Supplement; 4) Quissamã Group, based on Quissamã's Diet; 5) QG added with vitamins and minerals; 6) QGvm added with Food Supplement; and 7) QG added with Food Supplement. Water and food were offered ad libitum, and the weight of the animals and the food consumption were measured every two days. Blood was collected on the last day for biochemical analysis. The CGFS showed a significant weight loss $(p \leq 0.05)$ compared with all the other groups and significantly higher hemoglobin and hematocrit levels compared with the other Control Groups. The QG presented the highest hemoglobin level and the QGFS showed the highest hematocrit level among all the Quissamã Groups. The supplementation of Quissamã's Diet was not relevant in this experiment.

Index terms: weight gain, alternative supplementary feeding, hemoglobins, hematocrit.

\section{N T R O D U Ç Ã O}

O acompanhamento da situação nutricional das crianças de um país constitui instrumento essencial para aferição das condições de saúde da população infantil e oportunidade ímpar para serem adotadas medidas objetivas no sentido de combater a fome e atingir a segurança alimentar e nutricional adequada ${ }^{1}$. As deficiências nutricionais de maior importância epidemiológica, como a desnutrição energético-protéica (DEP), as anemias, a hipovitaminose $\mathrm{A}$ e o bócio, acham-se estreitamente associadas ao quadro estrutural da pobreza. A erradicação completa, definitiva e legítima, encontra-se na dependência da própria extinção dos grandes contrastes econômicos e sociais gerados e mantidos pelo processo de produção e distribuição dos bens e serviços. Urge, portanto, uma vigorosa ação de governo, respaldada pelo consenso da sociedade, como meio de reverter, a médio e longo prazo, o contexto político e social que condiciona as diferentes manifestações das carências alimentares e nutricionais².

Para a obtenção de provas mais sensíveis e definitivas sobre o estado de desnutrição é necessário realizar esta avaliação através de dados bioquímicos ${ }^{3}$. A anemia pode estar presente nos estados de desnutrição e pode ser complicada por deficiências de ferro e outros nutrientes, infecções associadas, infestação parasitária e absorção deficiente ${ }^{4}$.

A melhoria das condições nutricionais de uma população depende de amplo programa de desenvolvimento político, econômico e social. Como alternativa, para minimizar essa problemática, os programas de suplementação alimentar aparecem, enquanto não se solucionam os diversos fatores socioeconômicos que determinam a desnutrição. Várias questões têm sido propostas e colocadas em prática para a solução desta situação: uma delas é a utilização da alimentação alternativa, a qual visa o enriquecimento da dieta habitual da população, melhorando a sua qualidade através do fornecimento de um concentrado de minerais e vitaminas, resultando na promoção da saúde e combatendo a desnutrição e a anemia. Ela baseia-se na distribuição de alimentos visando o fornecimento adequado de energia e nutrientes para a dieta habitual da população infantil, de gestantes e de nutrizes ${ }^{5}$.

A Pastoral da Criança adotou o uso da multimistura composta das partes usualmente não 
consumidas dos alimentos: folhas (mandioca, batata-doce), cascas (ovo, banana), sementes (girassol, abóbora) e farelos (trigo e arroz), como alimentação alternativa em âmbito nacional e medida básica de saúde, junto com a vacinação, controle de diarréias, atenção pré-natal, controle de crescimento e promoção do aleitamento materno. Esta entidade vem trabalhando com alimentação alternativa desde 1987 e atuando com lideranças de diversas comunidades, com o intuito de minimizar a desnutrição na população infantil ${ }^{6}$.

O M inistério da Saúde (1994) criou um grupo de trabalho sobre Alimentação Alternativa que revisou uma série de estudos sobre o assunto, além das práticas exercidas pela Pastoral da Criança e por creches da Legião Brasileira de Assistência (LBA), concluindo ser urgente a realização de pesquisas científicas para esclarecer, definitivamente, todas as questões polêmicas ao redor dos produtos recomendados na alimentação alternativa?.

O Conselho Federal de Nutricionistas (CFN), em 1996, posicionou-se contrário à utilização da multimistura, em virtude da carência de estudos, comprovando a eficiência dos alimentos que a compõem e da influência de fatores antinutricionais ${ }^{8}$.

Em junho de 1999, a Vigilância Sanitária, através de Resolução sob o no 198, publicou, no Diário Oficial, uma consulta pública tendo como objetivo uma "Proposta de Regulamentação Técnica para Fixação de Identidade e Qualidade a que Deve Obedecer a Multimistura" 9 . Tendo tomado conhecimento a respeito deste documento e sabendo da importância do assunto para a saúde da população, o Conselho Regional de Nutricionistas - 4a Região (CRN-4) resolveu participar desta consulta pública enviando sugestões. Para formular suas sugestões, o CRN-4 promoveu uma discussão sobre a multimistura com uma equipe de profissionais da área da saúde, da área de ensino e da pesquisa, denominando-a "Grupo de Trabalho sobre M ultimistura" . Estes sugeriram mudanças na composição da multimistura: a adição do leite em pó, obrigatoriamente, e a retirada do pó da folha de mandioca, por esta apresentar em sua composição o ácido cianídrico. Estas propostas foram enviadas para a Vigilância Sanitária.

Em setembro de 1999, o CRN-4 promoveu novo seminário sobre a multimistura, onde vários profissionais expuseram seus trabalhos e experiências. A Pastoral da Criança estava presente, proporcionando, assim, oportunidade aos profissionais de trocarem experiências e conhecerem um pouco mais o trabalho realizado por esta entidade com a comunidade carente. Após algumas considerações e com base na posição do CFN sobre o assunto, foi recomendado, neste evento, que o nutricionista não prescrevesse ou indicasse a multimistura por não haver embasamento científico sobre sua eficácia como complemento nutricional a ser empregado no combate e prevenção da desnutrição infantil.

Em junho de 2000, a Vigilância Sanitária publicou a Resolução de Diretoria Colegiada (RDC), número 53, que dispõe sobre o Regulamento Técnico para Fixação de Identidade e Qualidade de Mistura à Base de Farelo de Cereais (antiga multimistura), na qual descreve requisitos a serem respeitados para o uso de misturas à base de farelos de cereais, não levando em consideração as sugestões encaminhadas pelo $\mathrm{CRN}-4^{10}$.

A Secretaria Municipal de Saúde (SMS) de Quissamã, RJ já utilizava alimentação alternativa no Subprograma da M ultimistura para suplementar a alimentação de crianças desnutridas inscritas neste programa ${ }^{11}$. A pós várias discussões, resolveu alterar a composição da sua multimistura básica, constituída de farelos de arroz e de trigo, sementes de abóbora e girassol, pó de folha de mandioca e casca de ovo ${ }^{12}$, passando a chamá-la de suplemento alimentar (SA), composta agora por farinha de trigo, aveia, fubá, gergelim, gérmen de trigo, leite em pó, extrato de soja, sementes de girassol e abóbora e casca de ovo; foram excluídos os alimentos não convencionais, como os farelos e folhas verdes, e a multimistura básica foi transformada em um novo suplemento. 
Em estudos realizados, em 1999, por Lucas \& Pandino ${ }^{13}$ e Lopes $\&$ Siqueira ${ }^{14}$, utilizando ratos desnutridos recebendo ração com $2 \%$ de proteína e posteriormente realimentados com a Dieta de Quissamã adicionada da multimistura ou de componentes isolados dela como suplemento, foi observada uma recuperação moderada da desnutrição implantada, com uma diminuição nos indicadores da concentração de proteínas totais e albumina sérica.

Nessas pesquisas, todas as rações foram adicionadas de misturas de vitaminas e minerais de acordo com a dieta AIN-93 recomendada pelo American Institute of Nutrition ${ }^{15}$, não sendo objeto de estudo analisar a influência destes nutrientes adicionados na recuperação da desnutrição dos ratos.

Considerando a ampla utilização da suplementação alimentar através de alimentos alternativos para recuperar a desnutrição em crianças de diversas regiões do Brasil, os quais consomem este suplemento diariamente em suas refeições com o intuito de recuperarem o seu estado nutricional deficiente, o desenvolvimento de estudos que avaliem o efeito dessa suplementação alimentar sobre o estado nutricional é relevante.

0 objetivo deste trabalho foi avaliar, em ratos, a qualidade nutricional e a influência do novo suplemento surgido com a modificação da composição da multimistura básica que era adicionada à dieta consumida por crianças desnutridas do município de Quissamã, RJ, com ou sem a adição de vitaminas e minerais segundo a dieta AIN-93, sobre o crescimento e indicadores bioquímicos.

\section{MATERIAL E MÉTODOS}

O ensaio biológico foi desenvolvido durante 28 dias com 42 Rattus norvegicus, variedade Albinus Rodentia mammalia da raça Wistar, machos, com idade média de 26 dias de vida, oriundos do Laboratório de Nutrição Experimental
(LABNE) do Departamento de Nutrição e Dietética da Faculdade de Nutrição da Universidade Federal Fluminense, sorteados aleatoriamente para formarem sete grupos com seis animais cada um: 1) (GQ) Grupo Quissamã, recebendo ração à base da dieta de Quissamã somente, sem adição de qualquer outro suplemento; 2) (GQvm) GQ adicionado das misturas de vitaminas e minerais; 3) (GQSA) GQ adicionado do Suplemento Alimentar; 4) (GQSAvm) GQ adicionado do Suplemento Alimentar e das misturas de vitaminas e minerais; 5) (GCvm) Grupo Controle (GC), recebendo ração à base de caseína, adicionado das misturas de vitaminas e minerais; 6) (GCSA) GC adicionado do Suplemento Alimentar; 7) (GCSAvm) GC adicionado do Suplemento Alimentar e das misturas de vitaminas e minerais. As rações que receberam adição das misturas de vitaminas $(1 \%)$ e de minerais $(3,5 \%)$ estavam de acordo com a dieta recomendada pela AIN-93 e o suplemento alimentar (SA) foi elaborado segundo as recomendações de Brandão \& Brandão (1988)5, adaptadas para o preparo de $100 \mathrm{~g}$ de ração. Todas as dietas apresentaram percentual de proteína em torno de 10,3\%. Durante o ensaio, os animais foram mantidos individualmente em gaiolas de polipropileno, em ambiente com temperatura e iluminação apropriadas. A água e a ração foram ofertadas ad libitum e o peso e o consumo de ração foram registrados a cada dois dias.

A Dieta de Quissamã foi elaborada com base no inquérito recordatório realizado pela equipe de profissionais da Secretaria Municipal de Saúde da Prefeitura de Quissamã, RJ, com 27 pais das crianças ( 0 a 5 anos) inscritas e participantes do Perfil Alimentar das Crianças do Subprograma da Multimistura. Através deste processo foi possível a elaboração da dieta que habitualmente as crianças consomem neste município, a qual foi denominada Dieta de Quissamã (Tabela 1).

Os alimentos foram preparados e transformados em ração no LABNE, através de técnica baseada no tipo de preparação relatada 
pelas famílias de Quissamã através do inquérito alimentar. Após o preparo, foram dessecados em estufa ventilada marca FABBE-PRIMAR, a $60^{\circ} \mathrm{C}$, durante $24 \mathrm{~h}$. Após secagem, os alimentos foram triturados em liqüidificador até a forma de pó. Para a obtenção da Dieta de Quissamã, todos os alimentos foram homogeneizados (Tabela 1). As rações foram preparadas com um percentual de 10,3\% de proteína. Conforme delineamento descrito anteriormente, algumas rações foram adicionadas das misturas de minerais e de vitaminas segundo as normas do Commitee... $(1979)^{16}$, modificadas de acordo com as recomendações da AIN-93G ${ }^{15}$ e/ou também foram adicionadas do suplemento alimentar alternativo.

Foram calculados os percentuais relativos às quantidades de cada alimento do suplemento alimentar (Tabela 2). A quantidade de suplemento alimentar utilizada nas rações foi equivalente ao valor utilizado pelas crianças participantes do Subprograma, o qual era de $20 \mathrm{~g}^{5}$, transformado em $100 \mathrm{~g}$ de ração para 0 rato, 0 que equivale a $2,1 \mathrm{~g}$. As amostras do suplemento alimentar foram adquiridas através da Secretaria Municipal de Saúde da Prefeitura de Quissamã, RJ.

Foram descritas as rações utilizadas no ensaio e suas respectivas composições (Tabela 3), destacando-se que as rações elaboradas com base na Dieta de Quissamã apresentam uma quantidade pequena de óleo em relação àquelas à base de caseína, pois a Dieta de Quissamã já possui óleo em sua composição.

O consumo da ração e o ganho de peso dos animais foram controlados a cada dois dias durante 28 dias de ensaio.

No final do ensaio, os animais foram anestesiados previamente para a coleta sangüínea, que foi feita por punção cardíaca, utilizando-se seringa e agulhas hipodérmicas. 0 sangue foi armazenado em tubos adicionados do anticoagulante (EDTA) para posterior determinação dos índices bioquímicos de hemoglobina e hematócrito, através dos kits da BIOCLIN.

0 método para determinação da hemoglobina baseia-se na oxidação do átomo de ferro (ferro II) da molécula de hemoglobina pelo ferricianeto de potássio, em pH fracamente alcalino, formando a metahemoglobina, a qual é convertida em cianometahemoglobina após a reação com o cianeto de potássio. A coloração avermelhada é proporcional à concentração de

Tabela 1. Constituintes da Dieta de Quissamã* utilizada para o preparo das rações.

\begin{tabular}{lc}
\hline Alimentos & Quantidade $(\mathrm{g})$ \\
\hline Ovo & 50 \\
Carne moída & 40 \\
Carne de porco & 10 \\
Pescada & 14 \\
Carne de frango & 50 \\
Arroz & 220 \\
Neston & 20 \\
Couve & 70 \\
Batata & 35 \\
Mandioca & 15 \\
Feijão & 102 \\
Açúcar & 35 \\
Manteiga & 2 \\
Leite & 40 \\
Banana & 60 \\
Laranja & 70 \\
Nescau & 13 \\
Óleo & 2 \\
\hline Total & 848 \\
\hline
\end{tabular}

*Fonte: Inquérito recordatório realizado pela SMS de Quissamã, RJ 1995.

Tabela 2. Constituintes do suplemento alimentar $(600 \mathrm{~g})$ e percentual correspondente de cada um.

\begin{tabular}{lcc}
\hline Constituintes & Quantidade $(\mathrm{g})$ & Porcentagem $(\%)$ \\
\hline Aveia & 100 & 16,66 \\
Farinha de trigo & 100 & 16,66 \\
Fubá & 120 & 20,00 \\
Gergelim & 40 & 6,66 \\
Gérmen de trigo & 40 & 6,66 \\
Leite em pó & 80 & 13,33 \\
Extrato de soja & 70 & 11,66 \\
Semente de abóbora & 20 & 3,33 \\
Semente de girassol & 20 & 3,33 \\
Casca de ovo & 10 & 1,66 \\
\hline Total & 600 & 100,00 \\
\hline
\end{tabular}

Fonte: Informações verbais da SMS - Quissamã, RJ-2000. 
hemoglobina presente na amostra, é lida em 500 a 540nm (ou em filtro verde) e segue a Lei de Beer. Para a determinação da hemoglobina, aplicou-se a técnica descrita por Lima et al. (1992) ${ }^{17}$, expressa em g/dL. Para efeito de comparação, utilizou-se como padrão a faixa de 11,0 a 18,0 g/dL estabelecida por Harkness \& Wagner (1993) ${ }^{18}$.

Para a determinação do hematócrito, foi empregada a técnica do microhematócrito (Lima et al., 1992 $)^{17}$, expressa em porcentagem (\%). Para efeito de comparação, utilizou-se como padrão a faixa de $36 \%$ a $48 \%$ estabelecida por Harkness \& Wagner $(1993)^{18}$.

Os dados foram avaliados através de análises de variância (ANOVA - One way), utilizando-se o Teste de Scheffe para observação da significância ao nível de $p \leq 0,05$. Obtendo-se valor significativo, foi aplicado o Teste de Bonferroni para determinar a diferença entre as variáveis. Utilizou-se o software Statgraphics Plus versão 6.0 .

\section{RESULTADOSE DISCUSSÃ O}

Foram levantados os dados da evolução ponderal (g) dos grupos (Tabela 4) e foram calculados os valores de ganho de peso (g), consumo alimentar ( $\mathrm{g}$ ) e índices bioquímicos de hemoglobina $(\mathrm{Hb} \mathrm{g} / \mathrm{dL})$ e de hematócrito $(\mathrm{Ht} \%)$ (Tabela 5).

Em relação ao peso inicial, todos os grupos encontraram-se dentro da mesma faixa numérica (Tabela 4); o GCSAvm, no entanto, apresentou valor abaixo dos demais. A valiando-se os dados de peso final, somente o GCSA demonstrou diferença estatística em comparação com os demais grupos. Com sete dias de ensaio, este grupo já apresentava diferença de ganho de peso em relação aos demais grupos. O GCSA, cuja ração foi deficiente em nutrientes como vitaminas e minerais, fundamentais para o bom crescimento e desenvolvimento dos animais, revelou ganho de peso insuficiente $(19,33 \mathrm{~g})$, comparado com a faixa de $159 \mathrm{~g}$ a $168 \mathrm{~g}$ dos demais. Este fato pode ter sido ocasionado pela inexistência de oligoelementos, como o zinco ${ }^{4}$, o qual, além de ser co-fator para muitas enzimas responsáveis pelo crescimento, está presente na gustina, um polipeptídeo salivar que parece ser necessário ao desenvolvimento normal das papilas gustativas.

Tabela 3. Composição das rações utilizadas pelos grupos durante 28 dias de ensaio.

\begin{tabular}{|c|c|c|c|c|c|c|c|}
\hline Nutrientes $\quad$ Grupos & GQ & GQSA & GQvm & GQSAvm & GCSA & GCvm & GCSAvm \\
\hline Caseína $^{1}$ & - & - & - & - & 13,49 & 13,49 & 13,49 \\
\hline Dieta de Quissama² & 76,68 & 76,68 & 76,68 & 76,68 & - & - & - \\
\hline Amido $^{3}$ & 17,07 & 15,27 & 12,52 & 10,67 & 62,86 & 60,16 & 58,36 \\
\hline M istura de Minerais ${ }^{4}$ & - & - & 3,50 & 3,50 & - & 3,50 & 3,50 \\
\hline Mistura de Vitaminas 5 & - & - & 1,00 & 1,00 & - & 1,00 & 1,00 \\
\hline Óleo ${ }^{6}$ & 0,70 & 0,40 & 0,75 & 0,50 & 6,00 & 6,30 & 6,00 \\
\hline Celulose $^{7}$ & 5,00 & 5,00 & 5,00 & 5,00 & 5,00 & 5,00 & 5,00 \\
\hline Colina $^{8}$ & 0,25 & 0,25 & 0,25 & 0,25 & 0,25 & 0,25 & 0,25 \\
\hline L-cistina $^{8}$ & 0,30 & 0,30 & 0,30 & 0,30 & 0,30 & 0,30 & 0,30 \\
\hline Suplemento Alimentar ${ }^{9}$ & - & 2,10 & - & 2,10 & 2,10 & - & 2,10 \\
\hline Açúcar ${ }^{10}$ & - & - & - & - & 10,00 & 10,00 & 10,00 \\
\hline Total & 100,00 & & 100,00 & 100,00 & 100,00 & 100,00 & 100,00 \\
\hline
\end{tabular}

1 = Comercial da Kauffmane Co; 2 = Elaborada segundo o Inquérito da Secretaria M unicipal de Saúde do município de Quissamã-RJ; $3=$ Maizena $^{\oplus} ; 4$ = Preparada segundo AIN-93 (elaborada p/RHOSTER/SP); 5 = Preparada segundo a AIN-93 (elaborada p/RHOSTER/SP); 6 - Liza ${ }^{\oplus}$; $7=$ Mocrocel $^{\circledR}$, Blanver Ltda; 8 = Fabricante Vetec; 9 =Alimentos alternativos preparados e consumidos no município de Quissamã; $10=$ Dolce $^{\circledast}$. 
Tabela 4. Peso inicial, com 7, 14, 21 e 28 dias, dos grupos experimentais durante o ensaio de 28 dias*.

\begin{tabular}{|c|c|c|c|c|c|}
\hline Variáveis & Peso Inicial & Peso com 7 dias & Peso com 14 dias & Peso com 21 dias & Peso com 28 dias \\
\hline \multicolumn{6}{|l|}{ GQ } \\
\hline $\bar{X} \pm s d$ & $69,50 \pm 1,91 a$ & $118,50 \pm 1,83 a$ & $158,00 \pm 3,07 a$ & $194,00 \pm 4,38 a$ & $228,66 \pm 4,70 a$ \\
\hline $\mathrm{CV}$. & 2,75 & 1,54 & 1,94 & 2,26 & 2,06 \\
\hline \multicolumn{6}{|l|}{ GQvm } \\
\hline $\bar{X} \pm s d$ & $68,50 \pm 2,10 a$ & $112,50 \pm 4,27 a$ & $150,33 \pm 7,39 a$ & $191,00 \pm 9,83 a$ & $228,33 \pm 10,21 a$ \\
\hline CV. & 3,07 & 3,80 & 4,92 & 5,15 & 4,47 \\
\hline \multicolumn{6}{|l|}{ GQSA } \\
\hline $\bar{X} \pm s d$ & $68,16 \pm 0,16 a$ & $112,66 \pm 2,29 a$ & $151,33 \pm 3,43 a$ & $191,16 \pm 4,15 a$ & $228,00 \pm 4,55 a$ \\
\hline $\mathrm{CV}$. & 0,23 & 2,03 & 2,27 & 2,17 & 2,00 \\
\hline \multicolumn{6}{|l|}{ GQSAvm } \\
\hline $\bar{X} \pm s d$ & $69,33 \pm 1,85 a$ & $111,50 \pm 2,34 a$ & $151,16 \pm 3,52 a$ & $190,00 \pm 3,46 a$ & $231,33 \pm 4,48 a$ \\
\hline CV. & 2,67 & 2,10 & 2,33 & 1,82 & 1,94 \\
\hline \multicolumn{6}{|l|}{ GCvm } \\
\hline $\bar{x} \pm s d$ & $67,16 \pm 1,62 a$ & $110,83 \pm 1,10 a$ & $155,00 \pm 2,40 a$ & $196,16 \pm 3,98 a$ & $235,66 \pm 5,12 a$ \\
\hline CV. & 2,41 & 0,99 & 1,55 & 2,03 & 2,17 \\
\hline \multicolumn{6}{|l|}{ GCSA } \\
\hline $\bar{X} \pm s d$ & $68,33 \pm 1,76 a$ & $81,83 \pm 4,41 b$ & $83,66 \pm 1,94 b$ & $87,50 \pm 2,04 b$ & $87,66 \pm 2,23 b$ \\
\hline $\mathrm{CV}$. & 2,57 & 5,38 & 2,31 & 2,33 & 2,54 \\
\hline \multicolumn{6}{|l|}{ GCSAvm } \\
\hline $\bar{x} \pm s d$ & $63,16 \pm 3,33 a$ & $108,00 \pm 6,07 a$ & $147,33 \pm 9,64 a$ & $190,33 \pm 9,65 a$ & $233,83 \pm 11,64 a$ \\
\hline $\mathrm{CV}$. & 5,27 & 5,62 & 6,54 & 5,06 & 4,97 \\
\hline
\end{tabular}

(*) Resultados médios $(\bar{X})$, desvios-padrão ( $\bar{X} \pm s d)$ e coeficiente de variação (cv); $n=6$ animais por grupo; ${ }^{\text {(abc) }}$ Letras diferentes denotam diferennça estatística entre grupos ao nível de $p \leq 0,05$.

As deficiências de zinco parecem ocasionar uma diminuição da acuidade gustativa, podendo provocar, nos ratos, uma menor ingestão de alimento e levando conseqüentemente, a um crescimento deficiente, fato observado neste estudo (Tabela 5), onde o consumo alimentar do grupo GCSA $(177,76 \pm 4,41 \mathrm{~g})$ foi inferior às médias dos demais, cujos valores variaram de $445 \mathrm{~g}$ a 380g. Dutra-de-Oliveira \& M archini $(1998)^{3}$ descrevem que, em animais de laboratório, um sinal precoce de deficiência deste mineral é a diminuição da ingestão alimentar, reforçando o achado neste ensaio. Devido à multiplicidade de funções do zinco, as manifestações de sua deficiência podem variar desde aquelas inespecíficas e discretas (apetite diminuído e paladar alterado) até uma clínica exuberante, como no caso de dermatite, hipogonadismo ou retardo do crescimento.
O cálcio presente no suplemento alimentar, tendo como fontes principais a casca do ovo e o leite em pó, em nada pôde contribuir para o ganho de peso dos ratos, provavelmente porque este mineral não estava disponível no conteúdo do SA, sendo insuficiente para que $o$ animal apresentasse um crescimento normal, destacando-se ainda a ausência da vitamina $D$, a qual é também de fundamental relevância no crescimento.

Em dietas desequilibradas em nutrientes, como no caso da ração à base de caseína sem a adição de vitaminas e minerais recomendada pela AIN-93G, o uso do SA causa grandes prejuízos aos valores de peso final dos animais, conforme se observou no grupo GCSA. A presença de fatores antinutricionais no SA, embora estes não tenham sido determinados, pode ser a explicação para este resultado, podendo ter acontecido a quelação dos minerais com esses fatores. Todos os grupos 
que tiveram suas rações adicionadas das misturas de vitaminas e minerais de acordo com a AIN-93G, ou tiveram a Dieta de Quissamã em sua ração, obtiveram uma curva de crescimento adequada, comprovando a importância desses nutrientes para o crescimento e desenvolvimento dos animais. Os grupos que receberam ração com a Dieta de Quissamã apresentaram valores superiores, comparados aos grupos controles, e somente 0 GCSA apresentou diferença significante dos demais.

Quanto à avaliação dos dados de hemoglobina $(\mathrm{Hb})$ (Tabela 5), nos grupos que consumiram a ração à base de caseína, o GCvm não apresentou diferença em relação ao GCSAvm. O GCSA obteve o maior valor de $\mathrm{Hb}$ $(16,16 \pm 0,34 \mathrm{~g} / \mathrm{dL})$, sendo diferente estatisticamente dos demais grupos controles, enquanto 0 GCvm revelou o menor valor encontrado no ensaio $(13,13 \pm 0,27 \mathrm{~g} / \mathrm{dL})$. Os grupos $\mathrm{GQ}$, GQSAvm, GQvm e GQSA não apresentaram diferença estatística entre si. O GQ obteve o maior valor de $\mathrm{Hb}(15,96 \pm 0,28 \mathrm{~g} / \mathrm{dL})$, enquanto 0 GQSAvm foi o grupo com menor valor $(14,96 \pm 0,14 \mathrm{~g} / \mathrm{dL})$ de $\mathrm{Hb}$ dentre os grupos que receberam a Dieta de Quissamã.

Em revisões bibliográficas, Ringler \& Dabich (1979) ${ }^{19}$ encontraram uma variação de $\mathrm{Hb}$ para ratos de $11,4 \mathrm{~g} / \mathrm{dL}$ a $19,2 \mathrm{~g} / \mathrm{dL}$, podendo haver alterações conforme raça, linhagem, idade, sexo e estado de saúde do animal. De acordo com estes valores, todos os grupos teriam o valor de $\mathrm{Hb}$ dentro dos padrões desejáveis. Em trabalhos experimentais, eles publicaram médias de $\mathrm{Hb}(\mathrm{g} / \mathrm{dL})$ para ratos machos W istar variando segundo a idade do animal: $13,6 \mathrm{~g} / \mathrm{dL}$ para ratos com seis semanas, $17,8 \mathrm{~g} / \mathrm{dL}$ para aqueles com 18 semanas e $16,8 \mathrm{~g} / \mathrm{dL}$ para os de 39 semanas;

Tabela 5. Ganho de peso, consumo de ração, hemoglobina e hematócrito dos grupos durante 28 dias*.

\begin{tabular}{|c|c|c|c|c|}
\hline Grupos & $\begin{array}{c}\text { Ganho de peso } \\
\text { (g) }\end{array}$ & $\begin{array}{c}\text { Consumo de ração } \\
\text { (g) }\end{array}$ & $\begin{array}{l}\text { Hemoglobina } \\
\text { (g/dL) }\end{array}$ & $\begin{array}{c}\text { Hematócrito } \\
(\%)\end{array}$ \\
\hline \multicolumn{5}{|l|}{ GQ } \\
\hline $\bar{X} \pm s d$ & $159,16 \pm 54,30 \alpha$ & $445,95 \pm 8,35 b c$ & $15,96 \pm 82,00 \alpha$ & $45,66 \pm 33,00 \alpha$ \\
\hline $\mathrm{CV}$. & 2,16 & 1,87 & 1,75 & 0,72 \\
\hline \multicolumn{5}{|l|}{ GQvm } \\
\hline $\bar{X} \pm s d$ & $159,83 \pm 45,80 \alpha$ & $440,75 \pm 17,15 b c$ & $15,15 \pm 33,00 \beta \alpha$ & $44,33 \pm 94,00 \alpha$ \\
\hline Cv. & 5,79 & 3,89 & 2,17 & 1,10 \\
\hline \multicolumn{5}{|l|}{ GQSA } \\
\hline $\bar{X} \pm s d$ & $159,83 \pm 92,40 \alpha$ & $429,91 \pm 11,97 a b c$ & $15,16 \pm 73,00 \beta \alpha$ & $46,00 \pm 63,00 \alpha$ \\
\hline $\mathrm{cV}$. & 2,68 & 2,78 & 2,44 & 0,80 \\
\hline \multicolumn{5}{|l|}{ GQSAvm } \\
\hline $\bar{x} \pm s d$ & $162,00 \pm 89,30 \alpha$ & $452,96 \pm 9,63 b c$ & $14,96 \pm 41,00 \beta \alpha$ & $43,33 \pm 12,00 \beta \alpha$ \\
\hline $\mathrm{cv}$. & 2,36 & 2,12 & 0,93 & 0,48 \\
\hline \multicolumn{5}{|l|}{ GCvm } \\
\hline $\bar{X} \pm s d$ & $168,50 \pm 93,60 \alpha$ & $395,50 \pm 11,92 a b$ & $13,13 \pm 72,00 \beta$ & $40,66 \pm 7,00 \beta$ \\
\hline cv. & 3,79 & 3,01 & 2,05 & 1,72 \\
\hline \multicolumn{5}{|l|}{ GCSA } \\
\hline$X \pm s d$ & $19,33 \pm 1,02 b$ & $177,76 \pm 4,41 d$ & $16,16 \pm 43,00 \chi \alpha$ & $44,50 \pm 52,10 \alpha$ \\
\hline cv. & 5,27 & 2,48 & 2,10 & 2,80 \\
\hline \multicolumn{5}{|l|}{ GCSAvm } \\
\hline $\bar{X} \pm s d$ & $170,66 \pm 9,19 a$ & $380,83 \pm 19,44 a$ & $13,88 \pm 0,14 b c$ & $45,50 \pm 0,76 a$ \\
\hline $\mathrm{CV}$. & 5,38 & 5,10 & 1,00 & 1,67 \\
\hline
\end{tabular}

(*) Resultados médios ( $\bar{X})$, desvios-padrão ( $\bar{X} \pm s d)$ e coeficiente de variação (cv); $n=6$ animais por grupo; (abc) Letras diferentes denotam diferennça estatística entre grupos ao nível de $p \leq 0,05$. 
os valores de $\mathrm{Hb}$ decrescem com a idade do animal. Considerando estes estudos, pode-se supor que os valores médios de $\mathrm{Hb}$ para este experimento, utilizando ratos de mesma linhagem, com idade média de 8 semanas, deveriam estar dentro do intervalo de $13,6 \mathrm{~g} / \mathrm{dL}$ a $17,8 \mathrm{~g} / \mathrm{dL}$. Seguindo este raciocícnio, todos os grupos apresentaram valores dentro deste limite, exceto o GCvm.

Para Harkness \& Wagner $(1993)^{18}$, os valores médios de $\mathrm{Hb}$ para roedores variam de $11 \mathrm{~g} / \mathrm{dL}$ a $18 \mathrm{~g} / \mathrm{dL}$. Considerando esta referência, todos os grupos apresentaram valor de $\mathrm{Hb}$ dentro deste intervalo.

Em relação aos grupos que consumiram a dieta controle, o GCSA apresentou o maior valor de $\mathrm{Hb}$ em detrimento de um crescimento satisfatório. Este grupo apresentou o menor crescimento dentre todos os grupos do ensaio (Tabela 4). Este fato pode indicar a ocorrência de um mecanismo compensatório do organismo para manter sua homeostase em níveis normais, ou até mesmo acima dele, deixando de crescer e se desenvolver. Sugere-se que uma das explicações seja a não-existência de oligoelementos, principalmente o zinco, na ração controle, ao contrário da ração à base da Dieta de Quissamã, nutricionalmente completa.

O GCVm obteve o menor valor de $\mathrm{Hb}$, mas em relação ao crescimento apresentou a maior variação de peso dentre todos os grupos do ensaio, ao contrário do GCSA. Pode-se dizer que isto se deve principalmente às vitaminas e aos minerais acrescidos à ração, pois estes nutrientes são essenciais como co-fatores para a evolução de um bom crescimento e para a prevenção de doenças. Entre os grupos que receberam ração à base da Dieta de Quissamã, observa-se o fato de o GQ ter apresentado um valor de $\mathrm{Hb}$ alto em relação aos demais e um nível de crescimento ótimo, indicando a superioridade desta dieta como fonte completa de nutrientes. O GQSA e o GQSA vm obtiveram valores abaixo do GQ, podendo-se explicar esse resultado pela presença do $S A$, o qual possuindo fatores antinutricionais em sua composição, pode ter impedido a completa absorção dos minerais presentes nestas dietas.

No tocante à análise de hematócrito $(\mathrm{Ht})$ (Tabela 5), dos grupos que consumiram a ração à base de caseína, o GCSAvm apresentou o maior valor numérico, semelhante ao GCSA. O GCvm obteve valor inferior de $\mathrm{Ht}(40,66 \pm 0,70 \%)$, com diferença significante $(p \leq 0,05)$ em relação aos outros grupos (valores acima de 44,33\% ).

Entre os grupos alimentados com a ração à base da Dieta de Quissamã não houve diferença significativa, tendo o GQSA apresentado o maior valor de $\mathrm{Ht}(46,00 \pm 0,36 \%)$. Ringler \& Dabich $(1979)^{19}$ publicaram médias de Ht para ratos machos Wistar "padrão em diversas idades" , com percentuais de $42,4 \%$ para 6 semanas e de 53,9\% para 18 semanas, devendo ser observado que estes valores têm tendência a diminuir com a idade avançada do animal, o qual apresenta o valor de 52,5\% com 39 semanas de vida. Tendo como parâmetro esta referência, ou seja, o intervalo de $42,4 \%$ a $53,9 \%$, para os ratos deste estudo, o GCvm apresenta Ht $(40,66 \pm 0,7 \%)$ abaixo do limite mínimo estabelecido.

Considerando os valores de média de $\mathrm{Ht} \%$ para roedores publicados por Harkness $\&$ Wagner $(1993)^{18}$, entre $36 \%$ e $48 \%$, todos os grupos deste experimento encontram-se dentro dos parâmetros normais. Deve-se ressaltar que os valores publicados por estes autores não especificam a idade, sexo ou linhagem dos animais.

O GCvm apresentou o menor valor de $\mathrm{Ht}$ acompanhado também do menor valor de $\mathrm{Hb}$, sugerindo uma possível anemia, em virtude de ambos os índices estarem baixos ${ }^{17}$.

O GQSA obteve o maior valor de $\mathrm{Ht}$, podendo tal resultado ser explicado pelo fato de sua ração ser rica em ferro, dando condições ao organismo do rato para ter uma boa produção de massa de células sangüíneas. Em relação ao crescimento,o GQSA também apresentou um ganho de peso satisfatório, sugerindo que a ração à base da Dieta de Quissamã, consumida por este grupo, tem papel importante em processos 
metabólicos, como na síntese de purinas, componentes estruturais do DNA e do RNA ${ }^{3}$.

\section{O N C L U S Ã O}

Com base nos resultados obtidos, pode-se concluir que o uso do SA se mostrou ineficiente na promoção de um crescimento adequado em rações nutricionalmente deficientes, mas aquelas que, além do SA, receberam a adição de vitaminas e minerais, ou a Dieta de Quissamã, apresentaram valores adequados.

Os grupos alimentados com rações adicionadas de misturas de vitaminas e minerais obtiveram valores ótimos de variação de peso, mostrando a importância desses nutrientes essenciais para o bom crescimento dos animais.

No entanto, a Dieta de Quissamã, sozinha, foi capaz de fornecer todos os nutrientes necessários para um crescimento ótimo e para a obtenção de bons índices bioquímicos entre os animais, sendo, portanto, desnecessária a sua suplementação.

\section{A G RADECIMENTOS}

Ao PIBIC/CNPq/UFF e FAPERJ pelas bolsas concedidas às alunas e a FAPERJ pelo auxílio à pesquisa $A P Q 1$, processo no E-26/170.613/2000.

\section{RE FERÊ NCIAS}

1. Valente FLS. Do combate à Fome à Segurança alimentar e nutricional: 0 direito à alimentação adequada. Rev Nutr PUCCAMP 1997; 10(1): 20-36.

2. Carlson BA, Wardlaw TM. A Global, regional and country assessment of child malnutrition. New York: Unicef Staff Working; 1990.

3. Dutra-de-Oliveira JE, Marchini JS. Ciências nutricionais. São Paulo: Sarvier; 1998.

4. Devlin TM, editor. Manual de bioquímica com correlações clínicas. São Paulo: Edgard Blücher; 2000.
5. Brandão $C T T$, Brandão RF. Alternativas alimentares. Brasília: Pastoral de Criança; 1988. (Publicado pela CNBB)

6. Beausset I. Estudio de las bases científicas para el uso de alimentos alternativos en la nutrición humana. Brasília: INAN; 1992.

7. Ministério da Saúde. Conclusões do Grupo de Trabalho sobre Alimentação Alternativa. Brasília: INAN; 1994. (M imeografado).

8. Conselho Federal de Nutricionistas. Posicionamento do Conselho Federal de Nutricionistas quanto à multimistura. Brasília; 1996.

9. Agência Nacional de Vigilância Sanitária (Brasil). Consulta pública: proposta de regulamento técnico para fixação de identidade e qualidade a que deve obedecer a multimistura. Resolução no 198 de 15 de junho de 1999. Diário Oficial da União; 1999.

10. Agência Nacional de Vigilância Sanitária da Saúde (Brasil). Resolução - RDC no 53, de 15 de junho de 2000. Dispõe sobre o Regulamento Técnico para Fixação de Identidade e Qualidade de Mistura à Base de Farelo de Cereais. Diário Oficial da União; 2000.

11. Scudieri APB, Souza EDM, Rodrigues JAO, Silveira LC, Batista SMS. Subprograma da multimistura Quissamã. Quissamã: Secretaria Municipal de Saúde; 1994.

12. Boaventura GT, Chiappini CCJ, Fernandes NRA, Oliveira EM. Avaliação da qualidade protéica de uma dieta estabelecida em Quissamã, RJ adicionada ou não de multimistura e de pó da folha de mandioca. Rev Nutr 2001; 13(3):201-9.

13. Lucas AMM, Pandino VRT. A utilização de multimistura, farelo de trigo e farelo de arroz para a recuperação da desnutrição. Estudo em ratos [monografia]. Niterói (RJ): Faculdade de Nutrição, Universidade Federal Fluminense; 1999.

14. Lopes JF, Siqueira AB. Influência da multimistura e da folha de mandioca nos índices bioquímicos em ratos [monografia]. Niterói (RJ): Faculdade de Nutrição, Universidade Federal Fluminense; 1999. 
15. Reeves PG, Nielsen FH, Jr Fahey GC. AIN-93 Purified diets for laboratory rodents: final report of the American Institute of Nutrition ad hoc writing committee on the reformulation of the AIN-76A rodent diet. J Nutr 1993; 123:1939-51.

16. Commitee on Laboratory Animal Diets. Assembly of Life Sciences. National Research Council. Control of Diet in Laboratory Animal Experimentation. Nutr Abstr Rev 1979; 40:413-9.

17. Lima AO, Soares JB, Gre JB, Galizzi J, Cançado JR. $M$ étodos de laboratório aplicados à clínica: técnica e interpretação. 7.ed. Rio de Janeiro: Guanabara; 1992.

18. Harkness JE, Wagner JE. Biologia e clínica de coelhos e roedores. 3.ed. São Paulo: Roca; 1993.

19. Ringler D, Dabich L. Hematology and Clinical Biochemistry. In: The Laboratory Rat. San Diego: Academic Press; 1979. p.105-19.

Recebido para publicação em 17 de agosto de 2001 e aceito em 12 de setembro de 2002. 